\title{
Osoby z niepełnosprawnością wzroku w świecie kultury - specyfika i uwarunkowania uczestnictwa inkluzywnego
}

\begin{abstract}
STRESZCZENIE
Rozważania teoretyczno-badawcze, a nade wszystko praktyka tyflopedagogiczna, każą upatrywać w partycypacji w kulturze osób z niepełnosprawnością wzroku ważnego kierunku oddziaływań edukacyjnych i rehabilitacyjnych, realizowanych w duchu inkluzji, czyli włączenia społecznego w istotne powiązania komunikacyjne, których kultura jest jednym z obszarów.

Na podstawie analizy opisowo-krytycznej nielicznej literatury przedmiotu, obserwacji uczestniczącej i osobistych doświadczeń autorki poddano refleksji problematykę specyfiki odbioru wytworów kultury przez osoby z niepełnosprawnością wzroku oraz uwarunkowań i możliwości ich pozawzrokowego udostępniania. Przedstawiono - odpowiadające specyfice procesów poznawczych osób niepełnosprawnych wzrokowo - dotykowo-słuchowe sposoby udostępniania sztuk wizualnych: system Braille’a, tyflografikę i audiodeskrypcję. Zwrócono uwagę na znaczenie Internetu dla partycypacji w kulturze osób niepełnosprawnych wzrokowo, przywołując wybrane egzemplifikacje. Na podstawie podjętych rozważań, wyprowadzono postulaty działań praktycznych i badawczych w zakresie interdyscyplinarnej problematyki inkluzywnego uczestniczenia w kulturze osób z niepełnosprawnością wzroku.
\end{abstract}

1 Małgorzata Czerwińska, Wydział Pedagogiki, Psychologii i Socjologii, Uniwersytet Zielonogórski, Polska, e-mail: m.czerwinska@wpps.uz.zgora.pl. 


\section{Słowa kluczowe:}

niepełnosprawność wzroku, sztuki wizualne, system Braille’a, tyflografika, audiodeskrypcja, partycypacja w kulturze

\section{ABSTRACT}

Theoretical and search considerations, and tyflopedagogic practice above all, make us see the culture of people with visual disabilities as an important way of educational and rehabilitation activities implemented in the spirit of inclusion, i.e. social inclusion in important communication links whose one of the areas is culture.

Based on a descriptive and critical analysis of small literature on the subject, as well as participant observation and personal experience of the author, the subject of the specific nature of the reception of works of culture by people with visual disabilities and the conditions and possibilities of non-visual ways of sharing them have been considered.

Tactile and auditory ways of providing visual arts: Braille system, typhlography and audio description have been presented as corresponding to the specificity of cognitive processes of visually impaired people. The importance of the Internet for participation in the culture of visually impaired people has been marked, recalling selected exemplifications.

Based on the considerations undertaken, the postulates of practical and research actions have been drawn up in the field of interdisciplinary issues of inclusive participation in the culture of people with visual disabilities.

\section{Keywords:}

visual disability, visual arts, Braille system, typhlographics, audio description, participation in culture

\section{WPROWADZENIE}

Problematyka aktywności kulturalnej osób z niepełnosprawnością jest zagadnieniem interdyscyplinarnym, zdatnym do wieloaspektowych rozważań: kulturoznawczych, pedagogicznych, psychologicznych, czy socjologicznych. Dotychczasowy dorobek piśmienniczy jest zróżnicowany wydawniczo-formalnie i odnosi się przede wszystkim do biernego uczestniczenia w życiu kulturalnym, aktywności twórczej osób z niepełnosprawnością, oddziaływań arteterapeutycznych (np. Hulek, 1989, 1991; Pichalski, 1984, 1992; Szulc, 1994; Żuraw, 1996; Konieczna, 2004; Baran, Olszewski, 2006; Czerwińska, 2007; Krawiecka, Śmiechowska-Petrovskij, Żelazkowska, 2016). 
Problematyka uczestniczenia w kulturze osób z niepełnosprawnością wzroku podejmowana jest nader rzadko. Prowadzono m.in. badania nad korzystaniem przez niewidomych ze środków masowego przekazu (np. Bendych, 1991), systemem L. Braille’a i czytelnictwem niewidomych (Czerwińska, 1999), twórczością literacką niewidzących autorów (Czerwińska, 2012), zastosowaniem tyflokartografii i audiodeskrypcji w udostępnianiu sztuk wizualnych (np. Mendruń, Oleksiak, 2010; Chmiel, Mazur, 2014; Karaszewska, 2015; Bernaś, 2017). Istotne, przeglądowe znaczenie mają opracowania zbiorowe (Czerwińska, 2008; Czerwińska, Dederko, 2008).

Wypada tu odnotować również komercyjny projekt „Nie bądź ślepy na kulturę! Uczestnictwo osób niewidomych w życiu kulturalno-artystycznym na przestrzeni lat 1989-2014”, zrealizowany w latach 2015-2017 przez Fundację Badań i Praktyk Społecznych i firmę „Far Beyond Business” - niestety, nie bez błędów metodologicznych i merytorycznych (http://www.kulturaslepych.pl).

Rozważania teoretyczno-badawcze, a nade wszystko praktyka tyflopedagogiczna, każą upatrywać w partycypacji w kulturze ważnego kierunku oddziaływań edukacyjnych i rehabilitacyjnych, realizowanych w duchu inkluzji, czyli włączenia społecznego w istotne powiązania komunikacyjne, których kultura, zarówno w jej szerokim (Kamiński za: Żuraw, 1996), jak i wąskim (Kłoskowska, 1983, 2007) rozumieniu jest jednym z obszarów.

Wypada zatem, na podstawie analizy opisowo-krytycznej nielicznej literatury przedmiotu, obserwacji uczestniczącej i osobistych doświadczeń autorki, poddać refleksji problematykę specyfiki odbioru wytworów kultury przez osoby z niepełnosprawnością wzroku oraz uwarunkowań i możliwości ich pozawzrokowego udostępniania - co w przypadku wzmiankowanych osób leży u podłoża inkluzywnego uczestniczenia w kulturze.

\section{UCZESTNICTWO W KULTURZE OSÓB Z NIEPEŁNOSPRAWNOŚCIĄ WZROKU I JEGO FUNKCJE}

Inkluzywny charakter partycypacji w kulturze oznacza obecność osób z niepełnosprawnością wzroku w symbolizacji, czyli w wyodrębnionych przez A. Kłoskowską (1972, s. 60 i nast.) społecznych ramach zachowań kulturalnych (społecznych układach kultury), tj. w bezpośrednich społecznych, nieinstytucjonalnych stycznościach ludzi (I układ); w przekazywaniu treści i wartości kultury w obrębie instytucji i różnych form organizacji życia kulturalnego (II układ); w istnieniu i funkcjonowaniu masowych, ponadlokalnych środków przekazu treści i wartości kultury (III układ). 
Należy tu nadmienić, że współcześnie owo uczestnictwo, traktowane jako proces komunikowania społecznego przekazującego system znaczeń symbolicznych i przypisywanych im wartości, obejmuje 5 modeli komunikacji kulturowej: kultura komunikacji bezpośredniej kultura stowarzyszeń i wolontariatu, kultura instytucji lokalnych - publicznych i prywatnych kultura masowa i popularna, cyberkultura - kultura społeczeństwa sieci (Sułkowski, 2005, s. 7).

Działania zmierzające do udostępniania dóbr kultury muszą uwzględnić prawo niepełnosprawnych wzrokowo odbiorców do indywidualnego udziału w zjawiskach kultury, które polega na: „przyswajaniu jej treści, używaniu jej dóbr, podleganiu obowiązującym w niej normom i wzorom, ale także tworzeniu nowych jej wartości oraz odtwarzaniu i przetwarzaniu istniejących - a zatem do wszelkiego kontaktu z wytworami kultury oraz zachowaniami kulturowymi, a tym samym bezpośredniego lub pośredniego kontaktu z innymi ludźmi” (Tyszka, 1971, s. 54).

Inkluzywne uczestniczenie w kulturze oznacza aktywność kulturalną wypełniającą funkcje normalizacyjne, do których H. Żuraw (1996) zalicza: kulturowo-synchronizacyjną, egzystencjalno-upodmiotawiającą, wspólnotową, kompensacyjno-katarktyczną, kreatywną, poznawczą, hedonistyczną, relaksacyjną. Realizacja tych funkcji odbywa się w procesie recepcji wytworów kultury, w trakcie którego powinno nastąpić przyswojenie składników warstw utworu: poznawczej, estetycznej, moralnej i strukturalno-kompozycyjnej. Na recepcję składają się zatem: doświadczenia poznawcze, uczuciowe, zainteresowania i postawy.

\section{PROCESY POZNAWCZE U NIEWIDOMYCH A ODBIÓR SZTUK WIZUALNYCH}

Specyfikę przebiegu procesów poznawczych u osób niepełnosprawnych wzrokowo (zwłaszcza niewidomych i ociemniałych) wyznacza zjawisko kompensacji kognitywnej na poziomie sensorycznym i percepcyjnym - tłumaczone teorią tworzenia się dynamicznych układów strukturalnych w obrębie I i II układu sygnałowego (I układ obejmuje zmysły, II układ - myślenie i mowę) (Grzegorzewska, 1964). Poznawanie rzeczywistości opiera się na polisensorycznym sposobie postrzegania złożonym z bodźców: dotykowych, słuchowych, węchowych, smakowych - prowadzącym do wytwarzania dotykowych i polisensorycznych schematów poznawczych. Integratorem sensorycznym jest zmysł dotyku (zmysł bliskonośny), współdziałający z pozostałymi analizatorami, m.in. mięśniowo-ruchowym i słuchu (zmysł dalekonośny). Zmysły dotyku i mięśniowy stanowią podstawowe, bezpośrednie źródło poznania przestrzennego niewidomych (Majewski, 2002; 
Czerwińska, 2004). Kompensację sensoryczną wspiera kompensacja werbalna, oparta na poznawczym wykorzystaniu funkcji mowy, czyli wspomaganiu poznania sensorycznego instrukcją słowną. Mowa jest tu czynnikiem informującym, instruującym, wyjaśniającym, kształtującym uczucia i sądy, formą komunikowania się i ekspresji (Śmiechowska-Petrovskij, 2014). Specyfiką procesów poznawczych niewidomego jest występowanie wyobrażeń surogatowych (zastępczych), wypełniających „luki” percepcyjne, będących wyrazem dążności do konstruowania w miarę adekwatnego obrazu rzeczywistości i posługiwania się językiem osób widzących. Dotyczą one stosunków przestrzennych, przedmiotów i ich cech oraz światła i barw. W ich tworzeniu istotną rolę pełnią mowa, myślenie analogiczne i wnioskowanie (Grzegorzewska, 1964).

W świetle powyższego refleksję musi budzić zagadnienie udostępniania osobom niepełnosprawnym wzrokowo bogatych gatunkowo sztuk wizualnych, obejmujących współcześnie: sztuki piękne (rysunek, malarstwo, rzeźba, rytownictwo, grafika, zdobnictwo książkowe, ilustrowanie książek, kaligrafia, architektura); sztuki współczesne (asamblaż, kolaż, sztuka zdobienia, sztuka konceptualna, instalacja, happening, sztuka performatywna, film, fotografia, sztuka wideo, animacja, grafika komputerowa, wydruki giclée, sztuka ziemi, grafitti); sztuki dekoratywne i rzemiosło (ceramika, garncarstwo, mozaika, sztuka kinetyczna, tapiceria, sztuka szkła); inne formy (projektowanie graficzne, projektowanie mody i wnętrz, sztuka zdobienia ciała - sztuka tatuażu, malowanie ciała); sztuki multimodalne (sztuka teatralna, sztuka filmowa, taniec) (Śmiechowska-Petrovskij, 2016).

Powyższa klasyfikacja sztuki jest wyrazem swoistego rodzaju okularcentryzmu, czyli zdominowania współczesnego świata - także kultury i sztuki - przez wizualność. W odniesieniu do niewidomych jest to zjawisko niebezpieczne - zagrażające ich procesom rozwojowym, jak również partycypacji społeczno-kulturalnej. Stąd też udostępnianie niewidomym sztuk wizualnych wymaga zarówno wiedzy tyflopsychologicznej i tyflopedagogicznej, jak i zabiegów organizacyjnych i infrastrukturalnych, zalecanych przez Narodowy Instytut Muzealnictwa i Ochrony Zbiorów (ABC..., 2013; Szymańska, 2011b).

Dotychczasowe rozwiązania wypracowane w obrębie muzealnictwa obejmują następujące formy udostępniania obiektów wizualnych: ścieżki dotykowe, trasy zwiedzania, zwiedzanie kuratorskie i lekcje muzealne; audiodeskrypcja wizualnych dzieł sztuki; opisy brajlowskie; tyflograficzne reprezentacje wizualnych dzieł sztuki; makiety trójwymiarowe; obiekty trójwymiarowe (oryginały, kopie, wydruki 3D, technika druku „Didú”); formy holistyczne - poznanie polisensoryczne (dotykowo-kinestetyczne, werbalno-muzyczne, węchowe, smakowe) (za: Śmiechowska-Petrovskij, 2016). 
Powyższe metody mają charakter haptyczny (oparte na percepcji dotykowej i kinestetyczno-ruchowej) i/lub akustyczny (informacje dźwiękowe niewerbalne, - np. muzyka oraz werbalne - opis słowny).

\section{SYSTEM BRAILLE'A I TYFLOGRAFIKA - DOTYKOWO-KINESTETYCZNE UCZESTNICZENIE W KULTURZE}

Opracowany przez L. Braille’a (1824 r.) system wypukłego pisma punktowego dla niewidomych (alfabet Braille’a) ciągle uznawany jest za doskonały sposób samodzielnego pisania i czytania. Jego tradycyjna wersja oparta jest na kombinacji 6 wypukłych punktów, dającej 63 znaki, z kolei wersja współczesna, komputerowa (tzw. Eurobraille) - na znaku ośmiopunktowym, co daje 256 znaków na zapisanie liter, cyfr, znaków interpunkcyjnych, matematycznych, chemicznych, fizycznych, informatycznych, notacji muzycznej (Czerwińska, 2003). W ocenie tyflologicznej znaczenie alfabetu Braille’a dla psychospołecznego funkcjonowania niewidomych jest bezsporne. Warunkuje nabycie umiejętności czytania i pisania, z uwzględnieniem zasad ortografii, interpunkcji gramatyki języka. Udostępnia różne źródła informacji: tekstowe, matematyczne, muzyczne, informatyczne, tyflograficzne. Zwiększa niezależność w życiu codziennym. Stwarza szanse edukacyjne zawodowe. Pozwala uczestniczyć w życiu społecznym, naukowym, technicznym, kulturalnym. Jest podstawą alfabetyzacji, zapobiegając analfabetyzmowi wśród niewidomych.

Podejmowany coraz częściej (także wśród tyflopedagogów) dyskurs - system Braille’a czy nowe technologie audialne - jest nieuzasadniony (Paplińska, 2015). Wpływa, niestety, na obniżanie rangi systemu, a tym samym poziom jego znajomości, co w połączeniu z rewolucją medialną pozwala przewidywać zmiany w jego funkcjonalności. Prognozuje się radykalne ograniczenie wydawania publikacji brajlowskich. System będzie wykorzystywany przez osoby niewidome głównie w pracy z komputerem oraz w sytuacjach życia codziennego (np. oznakowanie opakowań produktów żywnościowych, leków itd.). Cyfrowy system Braille’a (Eurobraille) będzie wykorzystywany do czytania wydawnictw elektronicznych przy użyciu brajlowskich technologii wspomagających. Podstawową formą książki dla niewidomych przestanie być książka papierowa, a stanie się książka cyfrowa (Czerwieńska, 2015).

Obserwuje się znikome wykorzystywanie przez niewidomych materiałów brajlowskich w udostępnianiu im obiektów sztuk wizualnych (opisy obiektów muzealnych, publikacje - np. katalogi wystaw, przewodniki, oznakowania przestrzeni muzealnej). 
Sięgająca swoją genezą XVIII wieku tyflografika (Czerwińska, 2017b) współcześnie pojmowana jest jako: „graficzne odwzorowanie rzeczywistości, użyteczne dla osoby niewidomej lub/i słabowidzącej, wykonane w dostępnej jej konwencji i skali, zredagowane w sposób umożliwiający i ułatwiający odczytanie dotykiem lub/i słabym wzrokiem przekazywanej grafiką informacji” (Jakubowski, 2009, s. 38).

Oparty na wiedzy tyflologicznej, kartograficznej, proces przeredagowania prezentacji płaskiej do postaci odpowiedniej dla niewidomego polega na: zmianie konwencji (sposobu przedstawienia), zmianie skali (powiększenie obrazu czytelnego dla widzących), zmianie poziomu generalizacji (rezygnacja z mniej istotnych treści), podziale treści ilustracji na kilka prezentacji tego samego obiektu wykonanych w tej samej lub w innej niż oryginał konwencji, zmianie linii, znaków i kolorów oryginalnego rysunku na zróżnicowane linie, faktury powierzchniowe (opracowanie tyflograficzne), uproszczeniu rysunku do prezentacji czytelnej dotykiem i uzupełnieniu opisem (Czerwińska, 2017b).

Poprawność wykonania tyflografiki, a więc jej zrozumiałość dla niepełnosprawnego wzrokowo użytkownika, zasadza się na stosowaniu dostępnych procesom poznawczym niewidomego konwencji rysunku: rysunek geometryczny figur płaskich i rysunek konstrukcyjny na płaszczyźnie, rysunek ilustracyjny w konwencji rzutu prostokątnego (widok) bez zbędnych szczegółów, rzut przedmiotu na jedną, dwie i trzy płaszczyzny, scena (rysunek kilku przedmiotów niezasłaniających się, rysunek przedmiotu w przekroju, plan izby, budynku, terenu, miasta, mapa w dowolnej skali i odpowiednim poziomie generalizacji). Obce sferze orientacyjno-poznawczej niewidomego są konwencje rzutu ukośnego (widok z lotu ptaka) i perspektywy zbieżnej (Chojecka i in., 2008).

Przygotowana zgodnie z wypracowanymi zasadami (Instrukcja..., 2011; Zasady..., 2011) tyflografika pełni ważne funkcje w społeczno-kulturalnym funkcjonowaniu osób z niepełnosprawnością wzroku. Informuje bowiem o: pojęciach przestrzennych, kształtach przedmiotów (widok, rzut, rzuty, przekrój), relacjach przestrzennych między przedmiotami (plan, mapa), pomagając poznać, zrozumieć i odwzorować pojęcia przestrzenne i rzeczywistość materialną, przekazać informacje o obiektach i zjawiskach niemożliwych do bezpośredniego poznania dotykowego (zbyt małe, zbyt delikatne, za duże, niebezpieczne lub poruszające się) (Więckowska, 2011; Czerwińska, 2017b).

W obszarze udostępniania treści kultury tyflografika ma zastosowanie w postaci reliefowych ilustracji i zdobnictwa książkowego, publikacji dotykowych (książki, albumy, broszury, ulotki, druki reliefowe), planów pomieszczeń, budynków, ogrodów botanicznych i zoologicznych, miast, miejsc użyteczności publicznej, re- 
liefowych przedstawień obiektów architektonicznych, barwnych map dotykowych (tematyczne, ogólnogeograficzne, historyczne, polityczne itp.). Niewątpliwym osiągnięciem polskiej tyflografiki, istotnym dla udostępniania dóbr kultury, są np. opracowania: Atlas polskie powstania narodowe (2017 r.), Atlas historyczny Polski (2016 r.), Atlas Parków Narodowych w Polsce (2014 r.), publikacje z cyklu Tyflografia polska: Żelazowa Wola - miejsce urodzenia Fryderyka Chopina (2015 r.), Bliżej Skarbów Kultury (2013 r.).

Niestety, praktyczne wykorzystanie tyflografiki w obszarze udostępniania dóbr kultury jest niewielkie, co wynika z niskiego poziomu edukacji graficznej polskich niewidomych (brak umiejętności odczytywania rysunków wypukłych) (Więckowska, 2009; Czerwińska, 2017b).

\section{AUDIODESKRYPCJA - DŹWIĘKOWO-WERBALNE UCZESTNICZENIE W KULTURZE}

Zapoczątkowany w latach 70. XX wieku system opisu słownego przekazów wizualnych, zwany audiodeskrypcją (AD), jest narracją, przekładem audiowizualnym, intersemiotycznym, wewnątrzjęzykowym (Jankowska, 2009; Szarkowska, 2009; Chmiel, Mazur, 2014; Trzeciakiewicz, br; Czerwińska, Grzelecka, 2017). Pozostaje bowiem w obszarze badań językoznawców, lingwistów czy tłumaczy językowych (Jankowska, 2009; Szarkowska 2009, Karaszewska, 2015), tyflopedagogów (np. Dycht, 2015; Czerwińska, Grzelecka, 2017), filmoznawców (np. Raczek, Więckowski, Künstler, 2011; Künstler, 2014). Wzbudza badawcze zainteresowanie samych jej adresatów i użytkowników (np. Szymańska, Strzymiński, 2010; Szymańska, 2011a; Kalbarczyk, Mirowski, 2015).

W ustawie o radiofonii i telewizji z 1992 r., znowelizowanej w 2011 r., definiowana jest jako: „werbalny, dźwiękowy opis obrazu i treści wizualnych zawartych w audycji audiowizualnej przeznaczony dla osób niepełnosprawnych z powodu dysfunkcji narządu wzroku, umieszczony w audycji lub rozpowszechniany równocześnie z audycją” (Ustawa..., 1992, 2011).

Audiodeskrypcja posiada coraz szersze zastosowanie, o czym świadczy jej typologia, wyróżniająca:

- audiodeskrypcję w sztukach wizualnych - wykorzystywaną w muzeach i galeriach sztuki, zazwyczaj w postaci plików dźwiękowych dołączanych do przewodników audio; opisuje dzieła z zakresu malarstwa, rzeźby, fotografii czy instalacji, obiekty architektury, krajobraz; 
- audiodeskrypcję na potrzeby ekranu (filmy, programy telewizyjne) występującą jako dodatkowa ścieżka dźwiękowa pomiędzy dialogami, opisującą elementy wizualne (gra aktorów, kostiumy, barwy i światło, scenografia);

- audiodeskrypcję w przedstawieniach na żywo - spektakle teatralne (wplataną pomiędzy dialogi aktorów), operowe, koncerty, przedstawienia taneczne;

- audiodeskrypcję widowisk sportowych - różniącą się od komentarza radiowego szczegółowym opisem lokalizacji zawodników, opisywaniem tego, co dzieje się na trybunach;

- audiodeskrypcję prasową (ilustracji prasowej) - stosowaną w elektronicznej wersji czasopism;

- audiodeskrypcję w materiałach edukacyjnych - stosowaną np. w multimedialnych środkach dydaktycznych (Chmiel, Mazur, 2014; Kalbarczyk, Mirowski, 2015; Berna, 2017; Czerwińska, Grzelecka, 2017).

Przygotowanie audiodeskrypcji regulują zasady (standardy), których ogólny zarys zawiera Ustawa o Radiofonii i Telewizji, a omawiają szczegółowo podręczniki - należy dokładnie poznać utwór/obiekt, który będzie opisywany; opis powinien odpowiadać na pytania: Kto?, Co?, Jak?, Gdzie?, Kiedy?; należy opisywać w myśl zasady - od ogółu do szczegółu; opis ma pobudzać wyobraźnię, używając bogatego słownictwa, porównań, metafor, epitetów; należy zachować obiektywizm, bez wartościowania, komentowania, interpretowania czy cenzurowania; opis musi być spójny, przemyślany i odpowiadać na potrzeby odbiorcy, ma być dostosowany do określonej grupy odbiorców, np. dzieci; tekst audiodeskrypcji przed odtworzeniem przez użytkownika powinien zostać poddany redakcji i ocenie innego redaktora/ konsultanta; jakość nagrania/odczytania tekstu powinna być bardzo dobra (Ustawa..., 2011; Żórawska,i in., 2012; Trzeciakiewicz, br).

A zatem - prawidłowo przygotowana audiodeskrypcja powinna cechować się zwięzłością (kondensacją), obiektywizmem i neutralnością. Zasady te leżą u podstaw zaleceń odnoszących się do poszczególnych rodzajów audiodeskrypcji, tj. audiodeskrypcji do produkcji audiowizualnych (filmowych i telewizyjnych) (Szymańska, Strzemiński, 2010; Kalbarczyk, Mirowski, 2015; Szarkowska, Künstler, br), dzieł plastycznych (Szymańska, 2011b; Golik-Gryglas, br), audiodeskrypcji ilustracji (np. fotografii prasowej) (Instrukcja..., 2013; Sadowska, 2014), audiodeskrypcji architektury (Bernaś, 2017).

Przykładowo, skrypt audiodeskrypcji dzieła wizualnego obejmuje:

- słowną etykietę - informacje podstawowe na temat dzieła, np.: rodzaj i tytuł dzieła, autor, rok powstania, epoka lub krąg kulturowy, technika wykonania, wymiary, informacja o własności dzieła, kolekcji; 
- opis ogólny: krótka informacja o temacie dzieła, głównych składowych, ich kompozycji, kolorystyce, atrybutach przestrzennych (np. w przypadku rzeźb);

- opis szczegółowy: poszczególnych elementów obrazu według kolejności nadanej w opisie ogólnym, dostarczający wyczerpujących informacji do rekonstrukcji umysłowej obrazu oraz sformułowania sądu estetycznego i interpretacji dzieła;

- opis sygnatury obrazu: np. lokalizacja i cechy;

- informacje dodatkowe: np. o technice dzieła, stylu, artyście, kontekście historycznym i kulturowym powstania dzieła, ciekawostki, anegdoty (za: Śmiechowska-Petrovskij, 2016).

Poprawnie przygotowana audiodeskrypcja ma istotne znaczenie dla partycypacji społeczno-kulturalnej osób niepełnosprawnych wzrokowo, ponieważ: umożliwia dostęp do wizualnych i audiowizualnych dóbr kultury, udostępnia edukacyjne produkty audiowizualne (multimedia), dostarcza opisu przedmiotów i zjawisk niemożliwych do poznania dotykowego, pomaga w przyswajaniu specjalistycznej terminologii związanej z różnymi dziedzinami nauki, stymuluje rozwój sfery orientacyjno-poznawczej, umożliwia samodzielne, aktywne i kompetentne włączanie się w życie społeczno-kulturalne, inspiruje wrażenia estetyczne, umożliwia doświadczanie piękna (Ciborowski, 2014; Kalbarczyk, Mirowski, 2015; Czerwińska, Grzelecka, 2017).

\section{PARTYCYPACJA W KULTURZE - MIĘDZY REALEM A SIECIĄ}

Działania na rzecz udostępniania osobom niepełnosprawnym wzrokowo tekstów kultury w dużej mierze należą do organizacji pozarządowych zajmujących się wsparciem i aktywizacją społeczną, np.: Fundacja Audiodeskrypcja http://www. audiodeskrypcja.org.pl/; Fundacja Kultury Bez Barier http://www. kulturabezbarier.org/; Fundacja na Rzecz Rozwoju Audiodeskrypcji „Katarynka”/http://www. fundacjakatarynka.pl/; Fundacja „Siódmy Zmysł”/http://www.siodmyzmysl.org/; Fundacja „Szansa Dla Niewidomych”/http://www.szansadlaniewidomych.org/.

Działania te realizowane są zarówno w przestrzeni realnej (np. uprzystępnianie obiektów muzealnych, przygotowywanie oferty muzealnej, szkolenie muzealników w zakresie obsługi osób z niepełnosprawnością wzroku, organizowanie seansów teatralnych i filmowych $\mathrm{z}$ audiodeskrypcją), jak i wirtualnej (np. prowadzenie baz skryptów audiodeskrypcji, audiodeskrypcji i tyflografiki dzieł plastycznych, filmów z audiodeskrypcją). 
Aktywność wzmiankowanych organizacji ma charakter projektowy, wspierany przez instytucje rządowe (np. Ministerstwo Kultury i Dziedzictwa Narodowego), działania realizowane są we współpracy z licznymi instytucjami kultury (np. Narodowe Centrum Kultury, Narodowy Instytut Audiowizualny, Krajowa Izba Producentów Audiowizualnych, Polski Instytut Sztuki Filmowej, Telewizja Polska, Narodowy Instytut Muzealnictwa i Ochrony Zbiorów).

Wśród wielości podejmowanych inicjatyw warto odnotować dla przykładu wieloletni projekt Fundacji „Katarynka” - „ADAPTER. Filmoteka bez barier. Portal filmowy dla niewidomych i niesłyszących”. „Adapter” jest pierwszym w świecie kinem w sieci dla niewidomych i niesłyszących użytkowników. Systematycznie powiększana baza zawiera ponad 80 filmów z audiodeskrypcją i napisami dla niesłyszących, a premierowe pokazy w sieci odbywają się raz w tygodniu (http:// www.adapter.pl). W ramach projektu organizowane są również pokazy filmowe z audiodeskrypcją i napisami dla niesłyszących w kinie „Nowe Horyzonty” we Wrocławiu. Od 2015 roku Fundacja prowadzi wersję projektu - „Adapter w Szkole”, który promuje edukację filmową dzieci i młodzieży oraz polską kinematografię.

Innowacyjnym projektem Fundacji „Katarynka”, Fundacji Siódmy Zmysł i Centrum Transferu Technologii „Emag”, zrealizowanym we współpracy m.in. z Uniwersytetem Jagiellońskim, a sfinansowanym przez Narodowe Centrum Badań i Rozwoju, jest aplikacja „Audiomovie” - system do obsługi audiodeskrypcji i audionapisów na potrzeby seansów kinowych i telewizji dla osób niepełnosprawnych wzrokowo, dyslektycznych, starszych, pozwalająca na samodzielne uczestniczenie w seansach kinowych przez odsłuchanie audiodeskrypcji na własnym smartfonie. Podczas seansu możliwe jest słuchanie audiodeskrypcji, wersji lektorskiej lub dubbingu w dowolnym języku. Rozwiązanie to daje możliwość współuczestniczenia i współprzeżywania, niezależnie od niepełnosprawności.

„Czytanie obrazów” to projekt Fundacji Kultury Bez Barier, przewidziany na lata 2016-2018 i służy zdigitalizowaniu i udostępnieniu w jednym miejscu dzieł sztuki plastycznej, będących w posiadaniu polskich muzeów. Platforma internetowa projektu zawiera stale wzbogacaną bazę zdigitalizowanych eksponatów, zaopatrzonych w: audiodeskrypcję, materiały dotykowe, tłumaczenia na polski język migowy, teksty uproszczone, zdjęcia, karty obiektów, opisy dzieł; definicje pojęć z zakresu sztuki w wersji filmowej YouTube, bazę Instytucji kultury objętych projektem (m.in.: Muzeum Śląskie w Katowicach, Muzeum Sztuki Współczesnej w Krakowie, Muzeum Historyczne Miasta Krakowa, Muzeum Łazienki Królewskie w Warszawie, Muzeum Narodowe w Warszawie, Muzeum Pałacu Króla Jana III w Wilanowie, Muzeum Rzeźby im. Xawerego Dunikowskiego w Królikarni, Muzeum Sztuki Nowoczesnej Zachęta - Narodowa Galeria 
Sztuki); wykaz realizowanych w kraju zajęć muzealnych przeznaczonych dla osób z niepełnosprawnością (zwiedzanie, warsztaty itp.) /http://www.czytanieobrazow. $\mathrm{pl} /$. Platformie internetowej towarzyszy aplikacja na systemy Android i iOS umożliwiająca otrzymywanie zdjęć, audiodeskrypcji i tłumaczeń na PJM - stworzonych do dzieł sztuki plastycznej oraz informacji o planowanych, w różnych miejscach w Polsce, przedsięwzięciach muzealnych, uwzględniających potrzeby osób z niepełnosprawnością. Wzmiankowane internetowe narzędzia (portal i aplikacja) są zaproszeniem do odwiedzenia w jednym miejscu wielu polskich muzeów i galerii, do poznania ich różnorodności, poczucia i zrozumienia zebranych przez nie dzieł.

Liczba instytucji kultury udostępniających swoje zbiory za pośrednictwem audiodeskrypcji rośnie systematycznie. Instytucje upubliczniają na swoich serwisach internetowych pliki audio, zawierające opisy wybranych kolekcji (np. Muzeum Narodowe, Muzeum Historyczne Miasta Krakowa). Korzystanie z nich oparte jest na dwóch opcjach: odtworzenie bezpośrednio w serwisie oraz zapisanie na dysku komputera lub w pamięci urządzenia mobilnego. Zdalny dostęp do audiodeskrybowanych zasobów muzealnych ułatwia niepełnosprawnemu wzrokowo odbiorcy merytoryczne i logistyczne przygotowanie się do zwiedzania wystawy. W trakcie zwiedzania osoby z niepełnosprawnością wzroku mogą korzystać z własnych urządzeń odtwarzających dźwięk (warunkiem jest uprzednie pobranie ścieżki audiodeskrypcji ze źródeł internetowych) lub posługiwać się odtwarzaczami stanowiącymi własność muzeum. Upowszechnianie audiodeskrypcji zbiorów muzealnych za pośrednictwem stron internetowych ułatwia dostęp do sztuki tym odbiorcom, którzy nie mają możliwości osobistego uczestnictwa w wystawie. Nie może to jednak w pełni zastąpić sytuacji bezpośredniego kontaktu ze sztuką, dającej doświadczenie pełnowartościowego przeżycia estetycznego.

\section{ZAKOŃCZENIE}

Działania na rzecz inkluzywnej partycypacji w kulturze osób niepełnosprawnych wzrokowo wynikają z obserwowanych po 1989 roku przemian w postawach społecznych wobec tych osób, przemian instytucjonalnych (powstawanie instytucji ogólnokrajowych i lokalnych na rzecz niewidomych), rozwoju organizacji i fundacji III sektora, rozwoju tyflotechnologii, przemian w postawach i zachowaniach samych niewidomych (aktywizacja tych osób w wymiarze społecznym, kulturalnym, edukacyjnym), zwiększeniu postaw indywidualistycznych - mniejsza identyfikacja ze środowiskiem niewidomych i specjalnymi placówkami edukacyjnymi. 
Refleksja nad inkluzywną obecnością osób niepełnosprawnych wzrokowo w kulturze opiera się o międzynarodowe i krajowe rozstrzygnięcia normatywne, podkreślające prawo tych osób do uczestnictwa w życiu społeczno-kulturalnym na równi z osobami pełnosprawnymi, określającymi zasady udostępniania wydawnictw, internetu, informacji osobom z niepełnosprawnością sensoryczną (Czerwińska, 2017a). Kluczowe znaczenie ma tu art. 30, obowiązującej w Polsce od 2012 roku, Konwencji ONZ o Prawach Osób Niepełnosprawnych - podnoszący prawo do uczestniczenia w życiu kulturalnym, zapewniane przez m.in.: korzystanie z materiałów dotyczących zagadnień kultury w dostępnych formatach; dostęp do programów telewizyjnych, filmów, teatru i innych form działalności kulturalnej w istniejących formatach; dostęp do miejsc, w których odbywają się wydarzenia kulturalne, tj.: teatrów, muzeów, kin, bibliotek oraz do usług związanych z działalnością kulturalną i turystyczną, do miejsc historycznych i ważnych z punktu widzenia kultury narodowej; zapewnienie, aby akty prawne dotyczące ochrony praw własności intelektualnej nie stanowiły nieracjonalnej bariery dyskryminującej osoby niepełnosprawne w dostępie do materiałów związanych ze sferą kultury (Konwencja..., 2012).

Wieloletnia obserwacja uczestnicząca autorki potwierdza wyniki oficjalnych raportów o poziomie realizacji zapisów Konwencji, wskazujących na niedostateczne wykorzystanie nowych technologii (np. tyflografika, audiodeskrypcja) w udostępnianiu dóbr kultury, znikomą liczbę programów telewizyjnych i filmów z audiodeskrypcją, nieprzestrzeganie standardów WCAG 2.0. przy tworzeniu stron internetowych, niedostateczne przestrzeganie przez wydawców zaleceń odnoszących się do udostępniania publikacji w formatach alternatywnych (Zadrożny, 2015; Czerwińska, 2017a).

Doświadczane przez niewidomych bariery w partycypacji w kulturze potwierdził projekt badawczy „Nie bądź ślepy na kulturę!” - wskazujący na: problemy z fizycznym dotarciem do instytucji kultury i poruszaniem się w ich przestrzeni, brak środków finansowych na korzystanie z dóbr kultury, brak dostosowanej do specyfiki odbioru przez niewidomych oferty kulturalnej w miejscu zamieszkania, zbyt małą liczbę filmów, przedstawień teatralnych z audiodeskrypcją, trudności z dotarciem do informacji o wydarzeniach kulturalnych, utrudniony dostęp do wydawnictw w formatach alternatywnych oraz ich oferta (http://www.kulturaslepych.pl).

W świetle powyższego wskazane jest opracowanie strategii działań na rzecz zwiększenia uczestnictwa w kulturze osób niepełnosprawnych wzrokowo, opartej na włączaniu problematyki niepełnosprawności w główny nurt polityki państwa i władz publicznych wszystkich szczebli. Strategia ta, leżąca w gestii Ministerstwa 
Kultury i Dziedzictwa Narodowego (MKiDN), zawierająca priorytetowe cele działań długoterminowych, powinna określić zasady ich finansowania, wskazując przede wszystkim na budżet państwa. Pozwoli to przełamać „słabe strony” mechanizmu konkursów grantowych (akcyjność i jednorazowość działań).

Rozważyć należy utworzenie wyspecjalizowanej instytucji kultury zajmującej się inicjowaniem i koordynacją działań na rzecz zwiększenia dostępu do kultury osób niewidomych (nawiązanie do tradycji Krajowego Centrum Kultury Niewidomych). Instytucja taka, za sprawą regularnego finansowania, umożliwiałaby realizowanie cyklicznych, długofalowych projektów, koordynowanie działań poszczególnych organizacji pozarządowych.

Niezbędne jest prowadzenie systematycznych szkoleń pracowników krajowych i lokalnych instytucji kultury z problematyki dostępności do kultury osób niepełnosprawnych wzrokowo oraz aktywizowanie i szkolenie liderów środowiska osób z niepełnosprawnością wzroku - w celu zwiększenia skuteczności działań organizacji pozarządowych na rzecz aktywizacji społeczno-kulturalnej.

Istotne znaczenie informacyjne i koordynacyjne ma stworzenie kompletnej bazy danych o działaniach instytucji podległych MKiDN, podejmowanych na rzecz ułatwienia dostępu do kultury osobom z niepełnosprawnością wzroku.

W świetle rewolucji medialnej zasadne jest podejmowanie działań na rzecz większego dostępu do dóbr kultury za pośrednictwem Internetu: teksty kultury dostosowane do percepcji osób niepełnosprawnych wzrokowo (filmy z audiodeskrypcją, audiobooki), budowa stron internetowych, kształcenie informatyczne i działania na rzecz zwiększenia dostępu do Internetu i urządzeń tyfloinformatycznych. Należy tu jednak zastrzec, że zapośredniczona (internetowa) partycypacja w kulturze nie może zastąpić uczestnictwa bezpośredniego - obecności w miejscach kultury, kontaktu z jej dziełami. Optymalnym rozwiązaniem jest zatem jednoczesne fizyczne i wirtualne dostosowanie instytucji kultury (np. muzeum), jej przestrzeni i zasobów (Jakubowski, 2011).

Rozważania nad partycypacją w kulturze osób niepełnosprawnych wzrokowo inspirują również do nakreślenia obszarów dalszych badań o charakterze interdyscyplinarnym, a więc prowadzonych przez pedagogów specjalnych (tyflopedagogów), pedagogów społecznych, socjologów (socjologów kultury), kulturoznawców, historyków sztuki, lingwistów.

Niezbędne są szerokie badania diagnostyczne, składające się z badań biernego i czynnego uczestnictwa w kulturze osób niepełnosprawnych wzrokowo w środowiskach lokalnych i jego uwarunkowań - co w konsekwencji powinno „zbudować” obraz aktywności społeczno-kulturalnej tych osób w Polsce. Postulat ten jest tym bardziej uzasadniony, że zauważa się brak badań nad uczestniczeniem w kulturze 
osób niewidzących, pozostających poza instytucjami edukacyjnymi i rehabilitacyjnymi. Podjęcie badań nad partycypacją w kulturze dorosłych osób niewidzących wydaje się głęboko uzasadnione, chociażby ze względu na możliwość włączenia oddziaływań kultury w proces rehabilitacji psychicznej i społecznej, realizowany przez organizacje pozarządowe.

Istotną częścią wzmiankowanych badań powinna być analiza lokalnych i krajowych działań instytucjonalnych i pozainstytucjonalnych na rzecz udostępniania dóbr kultury osobom niepełnosprawnym wzrokowo - szczególnie istotna wobec dużego rozproszenia informacji.

W przypadku niepełnosprawnych wzrokowo dzieci i młodzieży konieczne są badania nad kulturą czytelniczą i informacyjną, szczególnie uzasadnione wobec obserwowalnego spadku udziału w procesie edukacji systemu Braille’a na rzecz audialnych sposobów odbioru informacji tekstowej.

Rozwój tyflografiki i audiodeskrypcji skłania do dociekań o charakterze translatoryjnym nad adaptacją i przekładem intersemiotycznym wizualnych przekazów kultury, np. przezroczystość języka audiodeskrypcji, koncepcja audiodeskrypcji autorskiej, zależność między opisem a nazywaniem, techniki tyflograficzne a wywoływanie wrażeń ekwiwalentnych. Wskazane są tu również badania nad poznawczym i estetycznym oddziaływaniem metod udostępniania sztuk wizualnych, realizowane w nurcie dyskursu estetycznego, proponowanym przez E. Śmiechowską-Petrovskij (2016), wychodząc od tezy, że przeżycie estetyczne osób z niepełnosprawnością wzroku w kontakcie z wizualnymi dziełami sztuki należy rozumieć szeroko - jako dotykowe, słuchowe spostrzeganie obiektu estetycznego, wywołujące emocje i sądy estetyczne, jako dotykowe, słuchowe doświadczenie piękna, jako swoiste przeżycie percepcyjno-emocjonalne, wywoływane przez bodziec haptyczny i/lub werbalny lub polisensoryczny, niosący swoiste znaczenia, doświadczenia.

Zasadność podejmowania aktywności badawczej i praktycznej w obszarze uczestnictwa osób z niepełnosprawnością wzroku w kulturze wynika z jego integracyjnych, wspólnotowych, komunikacyjnych walorów. Przeżywanie dzieła sztuki, zwłaszcza w miejscu jego prezentacji, stwarza szeroką płaszczyznę kontaktu z innymi ludźmi i ich przeżyciami.

Inkluzywna partycypacja w kulturze osób z niepełnosprawnością wzroku to możliwość samodzielnego i kompetentnego odbioru sztuki, systematyczne i powszechne udostępnianie tekstów kultury - to dyskurs o potrzebie i możliwościach budowania społeczeństwa otwartego, świadomego, wolnego od stereotypów i uprzedzeń. 


\section{Bibliografia}

ABC Gość niepełnosprawny w muzeum. Szkolenia Narodowego Instytutu Muzealnictwa i Ochrony Zabytków 2013, 2.

Baran, J., Olszewski, S. (red.). (2006). Świat pełen znaczeń. Kultura i niepełnosprawność. Kraków: Oficyna Wydawnicza Impuls.

Bendych, E. (1991). Oczekiwania młodzieży niewidomej i słabowidzącej a środki masowego przekazu. W: A. Hulek (red.), Środki masowego przekazu a człowiek niepełnosprawny (s. 144-147). Warszawa: Polskie Towarzystwo Walki z Kalectwem.

Bernaś, A. (2017). Audiodeskrypcja oraz jej wykorzystanie w dostępie osób z uszkodzonym wzrokiem do informacji oraz świata kultury i sztuki. Rozprawa doktorska. Promotor prof. dr hab. B. Woźniczka-Paruzel. Instytut Informacji i Bibliologii. UMK. Toruń (mps, pdf, arch. aut.).

Chmiel, A., Mazur, I. (2014). Audiodeskrypcja. Poznań: Wydawnictwo Uniwersytetu im. Adama Mickiewicza.

Ciborowski, M. (2009). Znaczenie audiodeskrypcji dla niewidomych w Polsce. Przekładaniec, 20, s. 136-138.

Chojecka, A., Magner, M., Szwedowska, E., Więckowska, E. (2008). Nauczanie niewidomych dzieci rysunku. Przewodnik dla nauczyciela. Laski: Towarzystwo Opieki nad Ociemniałymi.

Czerwińska, M. (1999). Pismo i ksiqż̇ka w systemie L. Braille’a w Polsce. Historia i funkcje rewalidacyjne. Warszawa: Wydawnictwo Stowarzyszenia Bibliotekarzy Polskich.

Czerwińska, M. (2003). Alfabet Braille’a. W: Encyklopedia pedagogiczna XXI wieku. T. 1: A-F (s. 80-87). Warszawa: Wydawnictwo Akademickie Żak.

Czerwińska, M. (2004). Niewidomy. W: Encyklopedia pedagogiczna XXI wieku. T. 3: $M-O$ (s. 685-693). Warszawa: Wydawnictwo Akademickie Żak.

Czerwińska, M. (2007). Twórczość osób niepełnosprawnych. W: Encyklopedia pedagogiczna XXI wieku. T. 6: Su-U (s. 850-866). Warszawa: Wydawnictwo Akademickie Żak.

Czerwińska, M. (red.). (2008). Niewidomi w kulturze - od terapii do sztuki. Wybrane zagadnienia. Warszawa: Polski Związek Niewidomych.

Czerwińska, M. (2012). „Słowem potrafię wszystko”. O piśmienniczości autorów z niepełnosprawnościq wzroku. Studium bibliologiczno-tyflologiczne. Zielona Góra: Wydawnictwo Uniwersytetu Zielonogórskiego.

Czerwińska, M. (2015). System Braille’a -rewolucja medialna czy inkluzja społeczna osób z niepełnosprawnością wzroku? Przeglq̨d Biblioteczny, 3, s. 365-381.

Czerwińska, M. (2017a). Information culture of person with visual disabilities in typhlology and information science reflections. Interdyscyplinarne Konteksty Pedagogiki Specjalnej, 18, s. 29-52.

Czerwińska, M. (2017b). Tyflografika - szansa na nowe oblicze książki niewidomego i obecność jej użytkowników w świecie informacji? W kręgu rozważań bibliologiczno-tyflologicznych. Przeglad Biblioteczny, 85, 2, s. 169-184.

Czerwińska, M., Dederko, T. (red.). (2008). Niewidomi w świecie ksiq̨żek i bibliotek. Wybrane zagadnienia. Kielce: Oficyna Wydawnicza Ston 2.

Czerwińska, M., Grzelecka, E. (2017). Tyflografika i audiodeskrypcja - szansą na inkluzję społeczną osób z niepełnosprawnością wzroku? W: T. Żółkowska, I. Ramik-Mażewska 
(red.), Pedagogika specjalna - nowe obszary teorii i praktyki (s. 69-82). Szczecin: Wydawnictwo Uniwersytetu Szczecińskiego.

Dycht, M. (2015). Udostępnianie kultury obrazu osobom niewidomym i słabowidzącym z zastosowaniem audiodeskrypcji. Szkoła Specjalna, 3, s. 179-188.

Grzegorzewska, M. (1964). Wybór pism. Warszawa: PWN.

Hulek, A. (red.). (1989). Czas wolny ludzi niepetnosprawnych - zadania pedagoga. Wrocław, Warszawa, Kraków, Gdańsk, Łódź: Zakład Narodowy imienia Ossolińskich.

Hulek, A. (red.). (1991). Środki masowego przekazu a człowiek niepełnosprawny. Warszawa: Expograf.

Golik-Gryglas (b.r.). Audiodeskrypcja w sztukach plastycznych. Pobrane z: http://www. audiodeskrypcja.pl/sztukiplastyczne.html.

Instrukcja jak opisywać ilustracje osobom niewidomym (2013). Warszawa: Mazowieckie Stowarzyszenie Pracy dla Niepełnosprawnych „De Facto”.

Instrukcja tworzenia i adaptowania ilustracji i materiałów tyflograficznych dla uczniów niewidomych, opracowana przez zespół tyflopedagogów ze Specjalnych Ośrodków Szkolno-Wychowawczych w Polsce: Bydgoszcz, Kraków, Laski, Owińska 2011. Pobrane z: http://www.ore.edu.pl (Wydziały ORE $\rightarrow$ Specjalnych Potrzeb Edukacyjnych $\rightarrow$ Adaptacja podręczników).

Jakubowski, M. (2009). Tyflografika - historia i współczesność, metody i technologie. Tyfloświat, 1 (3), s. 36-40. Pobrane z: http://www.firr.org.pl/uploads/PUB/Tyfloswiat-01_2009.pdf.

Jakubowski, M. (2011). Przestrzeń muzealna przyjazna niewidomym. Tyfloświat, 4 (13), s. 3-6.

Jankowska, A. (2009). Audiodeskrypcja -wzniosły cel w tłumaczeniu. Między Oryginałem a Przekładem, XIV, s. 225-246.

Kalbarczyk, M., Mirowski, J. (2015). Świat opisywany dźwiękiem. Warszawa: Fundacja Szansa dla Niewidomych.

Karaszewska, K. (2015). Metody audiodeskrypcji i wpływ ich zastosowania na zrozumienie filmu przez odbiorców. Praca doktorska. Promotor prof. UW dr. hab. K. Hejwowski. Instytut Lingwistyki Stosowanej. UW. Warszawa. Pobrane z: http.//www.docplayer. pl/3465154-Metody-audiodeskrypcji-i-wplyw-ich-zastosowania-na-zrozumienie-filmuprzez-odbiorcow.html.

Kłoskowska, A. (1972). Społeczne ramy kultury. Warszawa: PWN.

Kłoskowska, A. (1983). Kultura masowa. Warszawa: PWN.

Kłoskowska, A. (2007). Socjologia kultury. Warszawa: Wydawnictwo Naukowe PWN.

Konieczna, E.J. (2004). Arteterapia w teorii i praktyce. Kraków: Oficyna Wydawnicza „Impuls”.

Konwencja ONZ o Prawach Osób Niepełnosprawnych. Dz.U. 2012, poz. 1169.

Krawiecka, K., Śmiechowska-Petrovskij, E., Żelazkowska, M. (2016). Sztuka/twórczość dostępna. Osoby z niepełnosprawnościami i chorobq psychicznq w kręgu recepcji i ekspresji sztuki. Warszawa: Wydawnictwo Uniwersytetu Kardynała Stefana Wyszyńskiego.

Künstler, I. (2014). Cel uświęca środki audiodeskrypcji. Przekładaniec, 28, s. 140-152.

Majewski, T. (2002). Tyflopsychologia rozwojowa. Psychologia dzieci niewidomych i słabo widzq̨cych. Warszawa: Polski Związek Niewidomych. 
Mendruń, J., Oleksiak, E. (red.). (2010). Tyflokartografia. Przegląd Tyflologiczny, 1-2. Warszawa: Polski Związek Niewidomych.

Paplińska, M. (2015). Młode pokolenie osób z niepełnosprawnością wzroku w paradoksie informacyjno-komunikacyjnym. W: K. Czerwińska, M. Paplińska, M. Walkiewicz-Krutak (red.), Tyflopedagogika wobec współczesnej przestrzeni edukacyjno-rehabilitacyjnej (s. 136-155). Warszawa: Wydawnictwo APS.

Pichalski, R. (1984). Uczestnictwo ludzi niepełnosprawnych $w$ kulturze $w$ porównaniu z ludźmi pełnosprawnymi. Warszawa: Centrum Naukowo-Badawcze Spółdzielczości Inwalidów CZSI.

Pichalski, R. (1992). Aspiracje kulturalne młodzieży niepełnosprawnej. Warszawa: Wydawnictwo SGGW.

Raczek, T., Więckowski, R., Künstler, I. (2011). Białq laskq po kinowym ekranie. Warszawa: Polski Instytut Sztuki Filmowej.

Sadowska, A. (2014). Audiodeskrypcja do ilustracji w prasie - wskazówki dla trenerów szkolących audiodeskryptorów. Przekładaniec, 28 s. 124-139.

Sułkowski, B. (2005). „Społeczne Ramy kultury” czterdzieści lat później. Pięć modeli komunikacji kulturowej. Kultura i Społeczeństwo, 2-3, s. 5-35.

Szarkowska, A. (2009). Przekład audiowizualny w Polsce - perspektywy i wyzwania. Przekładaniec, 1(20) s. 8-25.

Szarkowska, A., Künstler, I. (b.r.). Audiodeskrypcja w kinie, teatrze i muzeum. Wprowadzenie do działań praktycznych. W: M. Trzeciakiewicz (red.), Audiodeskrypcja w teorii i praktyce, czyli jak mówić o tym, czego nie można zobaczyć. Podręcznik do nauki audiodeskrypcji. Fundacja na Rzecz Rozwoju Audiodeskrypcji Katarynka. Pobrane z: http://docplayer.pl/5334175-Audiodeskrypcja-w-teorii-i-praktyce.html.

SZULC, W. (1994). Kulturoterapia. Wykorzystanie sztuki i działalności kulturalno-oświatowej w lecznictwie. Poznań: Wydawnictwa Uczelniane Akademii Medycznej im. Karola Marcinkowskiego.

Szymańska, B. (2011a). Audiodeskrypcja, czyli o tym, jak kultura audiowizualna staje się dostępna dla osób niewidomych. Tyfloświat, 4(13), s. 26-37. Pobrane z: http://www. firr.org.pl/uploads/PUB/tyfloswiat_4_13_2011.pdf.

Szymańska, B., (2011b). Rekomendacje dotyczq̨ce udostępniania instytucji audiodeskrypcji do dzieł plastycznych. Narodowy Instytut Muzealnictwa i Ochrony Zabytków. Pobrane z: http://nimoz.pl/upload/muzea_bez_barier/Rekomendacje_dotyczace_audiodeskrypcji_w_muzeach.pdf.

Szymańska, B., Strzymiński, T. (2010). Audiodeskrypcja. Obraz słowem malowany. Standardy tworzenia audiodeskrypcji do produkcji audiowizualnych. Białystok: Fundacja Audiodeskrypcja.

Śmiechowska-Petrovskij, E. (2014). Inny czytelnik - taka sama literatura? Wartościowanie książek literackich dla dzieci niewidomych w młodszym wieku szkolnym przez nauczycieli, wychowawców, bibliotekarzy. W: B. Jachimczak, K. Pawelczak, A. Wojciechowska (red.). Miejsce Innego we współczesnych naukach o wychowaniu. Inny w przestrzeni społecznej (s. 257-278). Poznań: Wydawnictwo Naukowe UAM. Śmiechowska, E. (2016). Kultura haptyczno-werbalna. Osoby niewidzące a sztuki wizualne - między doświadczeniem poznawczym i estetycznym. W: K. Krawiecka, 
E. Śmiechowska-Petrovskij, M. Żelazkowska, M. (red.). Sztuka/twórczość dostępna. Osoby z niepełnosprawnościami i chorobq psychicznq w kręgu recepcji i ekspresji sztuki (s. 57-126). Warszawa: Wydawnictwo Uniwersytetu Kardynała Stefana Wyszyńskiego. Trzeciakiewicz, M. (red.). (b.r.). Audiodeskrypcja w teorii i praktyce, czyli jak mówić o tym, czego nie można zobaczyć. Podręcznik do nauki audiodeskrypcji. Fundacja na Rzecz Rozwoju Audiodeskrypcji Katarynka. Pobrane z: http://docplayer.pl/5334175-Audiodeskrypcja-w-teorii-i-praktyce.html.

Tyszka, A. (1971). Uczestnictwo w kulturze. Warszawa: PWN.

Ustawa z dnia 25 marca 2011 roku o zmianie ustawy o radiofonii i telewizji oraz niektórych innych ustaw. Pobrane z: http://www.isap.sejm.gov.pl/DetailsServlet?id=WDU20110850459.

Ustawa z dnia 29 grudnia 1992 r. o radiofonii i telewizji(tekst ujednolicony). Pobrane z: http://www.krrit.gov.pl/dla-nadawcow-i-operatorow/regulacje-prawne/polska/.

Więckowska, E. (2009). Zasady redagowania tyflografiki. Tyfloświat, 3 (5), s. 7-13. Pobrane z: http://www.firr.org.pl/uploads/PUB/Tyfloswiat-03_2009.pdf.

Więckowska, E. (red.). (2011). Instrukcja tworzenia i adaptowania ilustracji i materiałów tyflograficznych dla uczniów niewidomych. Opracowana na zlecenie Departamentu Zwiększania Szans Edukacyjnych Ministerstwa Edukacji Narodowej, przez zespół tyflopedagogów ze Specjalnych Ośrodków Szkolno-Wychowawczych w Polsce w składzie: Marek Jakubowski (Owińska), Krystyna Kauba (Laski), Leszek Ogórek, Jolanta Ogórek (Kraków), Iwona Pawłowska (Warszawa), Alina Talukder (Owińska), s. Elżbieta Więckowska (Laski). Bydgoszcz, Laski, Kraków, Owińska (mps, Bibl. Tyfl., Laski).

Zadrożny, J. (red.). (2015). Społeczny Raport Alternatywny z realizacji Konwencji o prawach osób z niepełnosprawnościami w Polsce. Warszawa: Fundacja KSK.

Zasady tworzenia i adaptowania grafiki dla uczniów niewidomych, opracowane przez nauczycieli Specjalnych Ośrodków Szkolno-Wychowawczych dla Niewidomych i Słabo Widzqcych w Polsce (2011). Bydgoszcz, Laski, Łódź. Pobrane z: http://www.ore.edu.pl (Wydziały ORE $\rightarrow$ Specjalnych Potrzeb Edukacyjnych $\rightarrow$ Adaptacja podręczników). Żuraw, H. (1996). Uczestnictwo kulturalne młodzieży niepełnosprawnej. Warszawa: Wydawnictwo Akademickie Żak.

Żórawska, A, Więckowski, R., Künstler I., Butkiewicz U. (2012). Audiodeskrypcja-zasady tworzenia. Warszawa. Pobrane z: http://dzieciom.pl/wp-content/uploads/2012/09/ Audiodeskrypcja-zasady-tworzenia.pdf. 